\title{
Economic Evaluation of Intensive Inpatient Treatments for Severely Obese Children and Adolescents
}

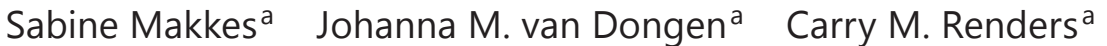 \\ Olga H. van der Baan-Slootweg ${ }^{b}$ Jacob C. Seidell ${ }^{a} \quad$ Judith E. Bosmans ${ }^{a}$ \\ a Department of Health Sciences and the EMGO Institute for Health and Care Research, VU \\ University Amsterdam, Amsterdam, The Netherlands; ${ }^{b}$ Merem Childhood Obesity Center, \\ Heideheuvel, Hilversum, The Netherlands
}

\section{Keywords}

Economic evaluation · Severe childhood obesity · Inpatient treatment · QALY

\begin{abstract}
Background: Considering the large economic consequences of severe childhood obesity for the society, we aimed to conduct an economic evaluation comparing two intensive 1-year lifestyle treatments with varying inpatient periods for severely obese children and adolescents with regard to standard deviation score BMI (SDS-BMI) and quality-adjusted life years (QALYs). Methods: An economic evaluation from a societal perspective accompanying a randomized controlled trial with a 24-month follow-up. 80 participants (8-19 years) with severe obesity were included. Participants received an intensive 1-year lifestyle treatment with an inpatient period of 2 months (short-stay group) or 6 months (long-stay group). Data were collected at baseline, 6, 12 , and 24 months and included SDS-BMI and QALYs. Results: SDS-BMI decreased in the first 6 months of treatment, stabilized in the second 6 months, and increased during the 2 nd year in both groups. After 24 months, SDS-BMI was similar in both groups, but remained lower than baseline values (mean difference $-0.24,95 \% \mathrm{CI}-0.42 ;-0.06$ ). There was no difference in QALYs between the groups after 24 months. For SDS-BMI, the probability of the short-stay treatment being cost-effective in comparison with the long-stay treatment was 1 at a willingness-to-pay of 0 EUR/unit of effect, which slowly decreased to 0.54 for larger willingness-to-pay values. Conclusions: Based on the results of this study, the short-stay treatment is considered to be more cost-effective from the societal perspective in comparison with the long-stay treatment. Future research should provide insight in whether the short-stay treatment is cost-effective in comparison with usual care.

(C) 2017 The Author(s)

Published by S. Karger GmbH, Freiburg
\end{abstract}

Prof. Dr. Jacob C Seidell

Department of Health Sciences, Faculty of Earth and Life Sciences

VU University Amsterdam

De Boelelaan 1085, 1081 HV Amsterdam, the Netherlands

j.c.seidell @vu.nl 


\section{Introduction}

During a period of three decades, the prevalence of obesity and severe obesity in children and adolescents has increased dramatically worldwide [1-6]. In the Netherlands, the prevalence of obesity was recently estimated to be $2.7 \%$ and $2.9 \%$ among boys and girls, respectively [6]. Of them, about $20 \%$ suffer from severe obesity, corresponding to approximately 18,500 Dutch children and adolescents [3].

Hyperlipidemia, hypertension, diabetes mellitus type 2, impaired respiratory and musculoskeletal conditions, and liver abnormalities are frequent complications of childhood obesity [7-11]. Severely obese children and adolescents are also more likely to suffer from psychosocial problems [12-14], and report quality-of-life scores similar to children diagnosed with cancer $[15,16]$.

Next to these physical and psychosocial complications, childhood obesity is related to increased healthcare utilization and costs [17-20]. Furthermore, when severe obesity is present in childhood, there is a high probability that it tracks into adulthood [21,22], leading to health problems and accompanying healthcare costs also later in life [21, 23]. When compared with normal-weight adults, men and women who were overweight/obese during their childhood were estimated to have 19,479 EUR and 14,524 EUR higher healthcare costs during their adulthood, respectively [24]. Thus, reductions in childhood obesity may lead to short-term economic benefits in children and longer-term benefits in adults [17, 25].

With regard to severe childhood obesity in particular, effective treatment could reduce the serious immediate and long-term burden on physical and psychosocial health of obese individuals and the society as a whole. However, severely obese children may warrant more intensive treatment than obese children [26, 27].

Currently in the Netherlands, Heideheuvel is the only specialized childhood obesity center offering treatment for severely obese children and adolescents. Originally, this intensive 1-year lifestyle treatment included a 6-month inpatient period. However, an inpatient period of 6 months is expensive and poses a considerable burden on both the participants and their families. Therefore, an adapted treatment was developed with a 2-month inpatient period [28].

Considering the large economic consequences of severe childhood obesity for the society, it is important to evaluate the cost-effectiveness of available treatments in order to help decision-makers determine which treatment should be reimbursed with the scarce resources available for healthcare. However, studies on the effectiveness of inpatient lifestyle treatments for severely obese children and adolescents are scarce [29,30], and, to the best of our knowledge, there are no studies on the cost-effectiveness of such treatments. Therefore, the aim of this study was to conduct an economic evaluation from a societal perspective comparing two intensive 1-year lifestyle treatments with varying inpatient periods (i.e. 2 months vs. 6 months) for severely obese children and adolescents with regard to standard deviation score BMI (SDS-BMI) and quality-adjusted life-years (QALYs).

\section{Patients and Methods}

Study Design and Population

An economic evaluation from a societal perspective was performed accompanying a randomized controlled trial with two treatment groups and a follow-up of 24 months. The Medical Ethics Committee of the VU University Medical Center (Amsterdam, the Netherlands) approved the study protocol. Prior to randomization, written informed consent was obtained from both the participants and their parents/caregivers. The treatment lasted 1 year after which the participants were followed up for another year. Details of the study have been described elsewhere [28]. 
Makkes et al.: Economic Evaluation of Intensive Inpatient Treatments for Severely Obese Children and Adolescents

Table 1. Dutch utility tariff [36]

\begin{tabular}{ll}
\hline Definitions & Coefficients \\
\hline Subtract if at least one level is at 2 or 3 & 0.071 \\
Subtract if mobility is at level 2 & 0.036 \\
Subtract if mobility is at level 3 & 0.161 \\
Subtract if self-care is at level 2 & 0.082 \\
Subtract if self-care is at level 3 & 0.152 \\
Subtract if usual activities is at level 2 & 0.032 \\
Subtract if usual activities is at level 3 & 0.057 \\
Subtract if pain/discomfort is at level 2 & 0.086 \\
Subtract if pain/discomfort is at level 3 & 0.329 \\
Subtract if anxiety/depression is at level 2 & 0.124 \\
Subtract if anxiety/depression is at level 3 & 0.325 \\
Subtract if any dimension is at level 3 & 0.234 \\
\hline
\end{tabular}

The study population consisted of 80 participants (8-19 years) with severe obesity. All participants were referred to a specialized childhood obesity center by their local pediatrician after insufficient response to ambulatory obesity treatment. Severe obesity was defined as SDS-BMI $\geq 3.0$ (99.9th age- and sex-specific percentile of BMI in the 4th Dutch nationwide growth study of 1997) or as SDS-BMI $\geq 2.3$ (99th age- and sexspecific percentile of BMI in the 4th Dutch nationwide growth study of 1997) in combination with obesityrelated comorbidity $[28,31]$.

\section{Intervention Conditions}

Both groups received an intensive 1-year lifestyle treatment with either an inpatient period of 2 months (short-stay group) or 6 months (long-stay group). The treatment focused on nutrition, physical activity, and behavior change and required active participation of the parents/caregivers. Treatment was delivered at a specialized childhood obesity center, Heideheuvel, in the Netherlands. A more detailed description of the content, frequency, and intensity of the treatment can be found elsewhere [28].

\section{Randomization and Masking}

The primary researcher, who was not blinded to treatment allocation, randomized all participants to the short-stay ( 40 participants) and long-stay group (40 participants) using a table of random numbers [32].

Because of the nature of the treatment, participants, their parents/caregivers, and healthcare professionals could not be blinded to the treatment.

\section{Effect Measures}

Data were collected at baseline, 6, 12, and 24 months and included SDS-BMI and QALYs.

BMI was calculated as weight $/$ height $^{2}\left(\mathrm{~kg} / \mathrm{m}^{2}\right)$. The degree of overweight was quantified using Cole's least mean square method, which normalizes the BMI's skewed distribution and expresses BMI as SDS-BMI [33]. SDS-BMI was calculated with the Growth Analyzer [34] using the 4th Dutch nationwide growth study of 1997 as reference[ 31].

QALYs were estimated using the EuroQol (EQ-5D) [35]. The EQ-5D descriptive system consists of five dimensions (mobility, self-care, usual activities, pain/discomfort, and anxiety/depression) with three levels of severity (no problems, some or moderate problems, extreme problems). Per dimension, participants were asked to choose the level that best described their current health status. The participants' EQ-5D health states were subsequently converted into utilities using the Dutch EQ-5D valuation tariff (table 1) [36]. Utilities represent quality of life in a single number with anchors at 0.0 (death) and 1.0 (full health). QALYs were subsequently calculated by multiplying the utility of a health state by the duration of time spent in a particular health state. Transitions between health states were linearly interpolated.

Costs

Costs were measured from a societal perspective, including the costs of treatment, healthcare, transportation, and lost productivity of the parents/caregivers. The societal perspective is advocated by the Dutch Manual of Costing [37] and provides insight into the net effect across all stakeholders. Hereby, it indicates 
Makkes et al.: Economic Evaluation of Intensive Inpatient Treatments for Severely Obese Children and Adolescents

Table 2. Price weights used for the valuation of resources consumed during treatment and follow-up

\begin{tabular}{ll}
\hline & Unit cost, EUR 2010 \\
\hline $\begin{array}{l}\text { Direct healthcare costs } \\
\text { Primary care }\end{array}$ \\
General practitioner (per visit) & 28.35 \\
Dietitian (per visit) & 27.33 \\
Mental healthcare & \\
Social worker (per visit) & 65.80 \\
Psychologist (per visit) & 80.99 \\
Physical therapy & \\
Physiotherapy (per visit) & 36.44 \\
Cesar therapy (per visit) & 35.43 \\
Haptonomy (per visit) & 36.44 \\
Manuel therapist (per visit) & 35.43 \\
Orthopedist (per visit) & 72.89 \\
Secondary care & \\
Outpatient clinic (per visit) & 72.89 \\
Direct non-healthcare costs & \\
Transport, km & \\
Car & \\
Public transport & 0.20 \\
Indirect non-healthcare costs & 0.20 \\
Absenteeism paid labor (per hour) & \\
Father & \\
Mother & 32.89 \\
\hline
\end{tabular}

whether the societal costs of an intervention are less than the benefits experienced by all stakeholders, rather than simply e.g. the healthcare sector's costs being less than its benefits [38, 39]. Table 2 lists the cost categories and unit prices used in this study. Treatment costs were estimated based on prices paid. Healthcare utilization, transportation, and lost productivity data were collected using cost dairies, which were sent to the parents/caregivers every 3 months.

Dutch standard costs were used to value healthcare utilization [37]. Transportation costs were estimated in accordance with the Dutch manual of costing [37]. Lost productivity consisted of hours taken off from work by parents/caregivers because of the treatment. Average sex-specific productivity costs per working hour were used to estimate lost productivity costs [37]. All prices were adjusted to 2010 EUR using Dutch price index figures [40]. This reference year was chosen, as the majority of the participants' resource use occurred in 2010. In accordance with the Dutch Manual of Costing, costs and effects occurring during the 2nd year of follow-up were discounted at a rate of $4 \%$ and $1.5 \%$, respectively [37].

\section{Statistical Analyses}

The sample size was calculated to detect a 0.5 SDS-BMI difference between the two groups after 1 year of treatment which is considered a clinically meaningful effect size [41]. Based on a power of $80 \%$ and a twotailed significance level of 5\%, two groups of 40 participants were needed [28].

Analyses were performed according to the intention-to-treat principle. Baseline characteristics were compared between the two treatment groups and between participants with and without complete followup. Independent Student's t-tests were used for continuous variables and chi-square tests for categorical variables using IBM SPSS Statistics for Windows, Version 21 (SPSS 21; Armonk, NY, USA). Statistical significance was set at a $\mathrm{p}$ value $<0.05$.

Missing data were imputed using multiple imputation, stratified by treatment group. Sex, household situation, ethnicity and Socio-Economic Status were used as predictors in the imputation model. Using predictive mean matching and fully conditional specification, 15 complete data sets were created in SPSS 21 (loss of efficiency $\leq 5 \%$ ) [42]. Pooled estimates were calculated according to Rubin's rules [42].

Both a cost-effectiveness analysis (CEA) and a cost-utility analysis (CUA) were performed. Effectiveness at 24-month follow-up was analyzed using linear regression, adjusted for baseline values. 95\% confidence intervals (95\% CIs) around differences in total and disaggregated costs were estimated using bias corrected 
Makkes et al:: Economic Evaluation of Intensive Inpatient Treatments for Severely Obese Children and Adolescents

and accelerated bootstrapping with 5,000 replications. With bootstrapping, statistical analyses are based on repeatedly resampling with replacement from the observed data [39]. Seemingly unrelated regression (SUR) analyses were performed to estimate cost and effect differences while taking into account the correlation between costs and effects [43]. Subsequently, incremental cost-effectiveness ratios (ICERs) were calculated by dividing the total cost differences by the effect differences. The uncertainty surrounding the ICERs was graphically illustrated by plotting bootstrapped incremental SUR on cost-effectiveness planes (CE-planes) [44]. Finally, a summary measure of the joint uncertainty of costs and effects was presented using cost-effectiveness acceptability curves (CEACs). CEACs indicate the probability of an intervention being cost-effective in comparison with usual care at different values of willingness-to-pay (i.e. the maximum amount of money decision-makers are willing to pay per unit of effect gained) [45]. These analyses were performed with Stata Statistical Software version 12 (College Station, TX, USA).

Sensitivity Analyses

Two sensitivity analyses were performed to test the robustness of the results. In the first sensitivity analysis, the analyses were repeated without discounting of costs and effects. In the per protocol analysis, only participants who took part in at least $75 \%$ of the treatment sessions were included. A post-hoc analysis was performed stratified for sex.

\section{Role of the Funding Source}

The study is funded by The Netherlands Organization for Health Research and Development (ZonMw). The funder had no role in design and conduct of the study; collection, management, analysis, and interpretation of the data; preparation, review, or approval of the manuscript; and decision to submit the manuscript for publication.

\section{Results}

\section{Participants}

In total, 169 participants were referred by their local pediatrician after insufficient response to ambulatory obesity treatment. Of them, 89 were excluded based on either a decision made by the staff of Heideheuvel $(\mathrm{N}=46)$ or by the family $(\mathrm{N}=43)$. This left 80 participants to be included in the study (fig. 1).

At baseline, no relevant differences were found between the two treatment groups (table 3). Complete follow-up was obtained from 24 short-stay and 25 long-stay group participants $(61 \%)$ on the effect measures. 55\% had complete cost measures in the 1 st half year, $40 \%$ in the 2 nd half year, $61 \%$ in the 3 rd half year, and $24 \%$ in the 4 th half year. There were no statistically significant differences in baseline characteristics between participants with and without complete follow-up.

\section{Effectiveness}

SDS-BMI decreased in the first 6 months of treatment, stabilized in the second 6 months and increased during the 2nd year in both groups. The increase in SDS-BMI in the long-stay group was larger than in the short-stay group (fig. 2). After 24 months, SDS-BMI was similar in both groups, but remained lower than baseline values (mean difference 24 months and baseline $-0.24,95 \%$ CI $-0.42 ;-0.06)$.

The mean utility score was $0.77 \pm 0.04$ (mean \pm standard error (SE)) in the short-stay group at baseline and $0.88 \pm 0.02$ and $0.87 \pm 0.02$ after 12 and 24 months, respectively. The mean utility scores for the long-stay group were $0.80 \pm 0.03,0.91 \pm 0.01$ and $0.90 \pm 0.02$ at baseline, after 12 and after 24 months respectively. The mean number of QALYs gained after 24 months was $1.68 \pm 0.03$ in the short-stay group and $1.75 \pm 0.03$ in the long-stay group; however, this was not statistically significant (mean difference $-0.07,95 \%$ CI $-0.16 ; 0.02$ ) (table 4). 
Makkes et al:: Economic Evaluation of Intensive Inpatient Treatments for Severely

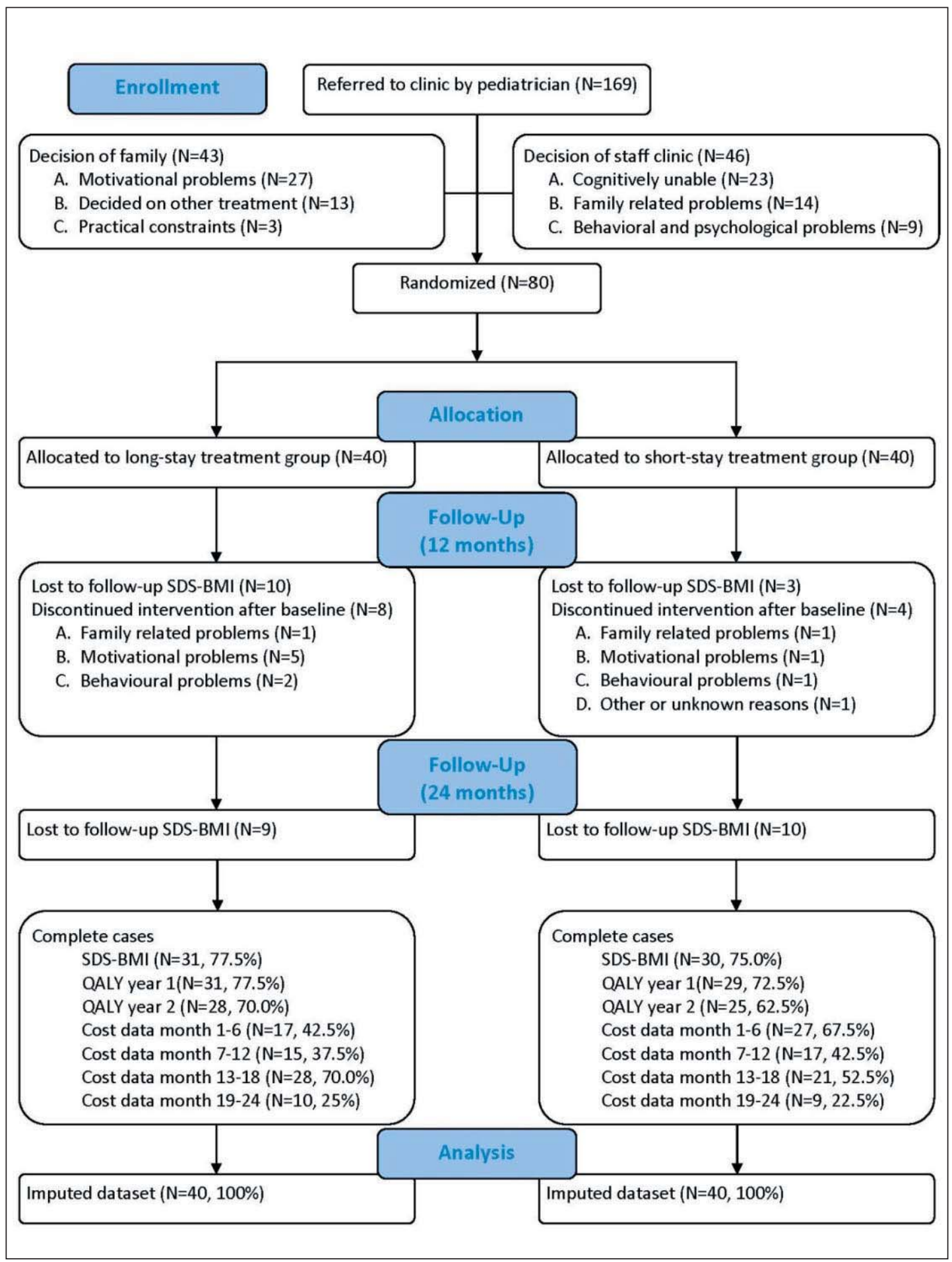

Fig. 1. Flow diagram of participants. 
Makkes et al.: Economic Evaluation of Intensive Inpatient Treatments for Severely Obese Children and Adolescents

Table 3. Baseline characteristics of the study population

\begin{tabular}{|c|c|c|c|}
\hline & $\begin{array}{l}\text { Total } \\
\mathrm{N}=80\end{array}$ & $\begin{array}{l}\text { Short-stay group } \\
\mathrm{N}=40\end{array}$ & $\begin{array}{l}\text { Long-stay group }{ }^{b} \\
\mathrm{~N}=40\end{array}$ \\
\hline Mean age, years & $14.8 \pm 2.3$ & $14.5 \pm 2.4$ & $15.0 \pm 2.2$ \\
\hline Female, n (\%) & $53(66.3)$ & $28(70.0)$ & $25(62.5)$ \\
\hline \multicolumn{4}{|l|}{ Ethnicities (\% of total) } \\
\hline Western & 61.5 & 69.2 & 53.8 \\
\hline Non-Western & 38.5 & 30.8 & 46.2 \\
\hline \multicolumn{4}{|c|}{$\begin{array}{l}\text { Educational level of the parents/caregivers } \\
(\% \text { of total) })^{c}\end{array}$} \\
\hline Low & 38.7 & 38.5 & 38.9 \\
\hline Medium/intermediate & 42.7 & 43.6 & 41.7 \\
\hline High & 18.7 & 17.9 & 19.4 \\
\hline \multicolumn{4}{|l|}{ SES (\% of total) } \\
\hline Below average & 65.8 & 59.5 & 71.8 \\
\hline Above average & 34.2 & 40.5 & 28.2 \\
\hline \multicolumn{4}{|l|}{ Household situation ( $\%$ of total) } \\
\hline Married/living together & 55.0 & 62.5 & 47.5 \\
\hline Divorced & 33.8 & 32.5 & 35.0 \\
\hline One-parent family(mother) & 7.5 & 2.5 & 12.5 \\
\hline Other situation & 3.8 & 2.5 & 5.0 \\
\hline Mean SDS-BMI & $3.4 \pm 0.39$ & $3.4 \pm 0.39$ & $3.4 \pm 0.39$ \\
\hline
\end{tabular}

EQ-5D = EQ-5D descriptive system; SD = standard deviation; SDS-BMI = standard deviation of BMI; SES = socioeconomic status.

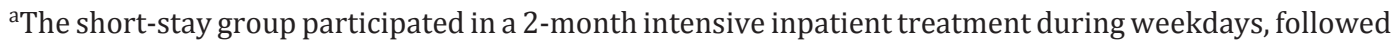
by biweekly return visits of 2 days during the next 4 months, then followed by 6 monthly return visits of 2 days.

${ }^{\mathrm{b}}$ The long-stay group participated in a 6-month intensive inpatient treatment during weekdays, followed by 6 monthly return visits of 2 days.

${ }^{c}$ Educational level was classified according to the definition of Statistics Netherlands (www.cbs.nl).

Table 4. Multiply imputed pooled mean costs and effects per participant in the long-stay group and shortstay group and mean cost and effect differences between both groups during the 24-month follow-up

\begin{tabular}{llll}
\hline $\begin{array}{l}\text { Outcome } \\
\text { Clinical outcome }\end{array}$ & $\begin{array}{l}\text { Short-stay group } \\
\mathrm{N}=40\end{array}$ & $\begin{array}{l}\text { Long-stay group } \\
\mathrm{N}=40\end{array}$ & $\begin{array}{l}\text { Mean difference } \\
(95 \% \mathrm{CI})^{*}\end{array}$ \\
$\begin{array}{l}\text { SDS-BMI } \\
\text { QALY }\end{array}$ & $3.20 \pm 0 \cdot 13$ & $3.18 \pm 0.13$ & $0.02(-0.30 ; 0.33)$ \\
& $1.68 \pm 0 \cdot 03$ & $1.75 \pm 0.03$ & $-0.07(-0.16 ; 0.02)$ \\
\hline $\begin{array}{l}\text { Cost category } \\
\text { Treatment }\end{array}$ & & & \\
Healthcare & & & \\
$\quad \begin{array}{l}\text { Primary healthcare } \\
\quad \text { Secondary healthcare }\end{array}$ & $1,018 \pm 203$ & $425 \pm 111$ & $-24,289(\mathrm{NA})$ \\
$\begin{array}{l}\text { Transportation } \\
\text { Lost productivity }\end{array}$ & $1568 \pm 192$ & $294 \pm 86$ & $573(219 ; 1,158)$ \\
Total costs & $1,137 \pm 69$ & $131 \pm 32$ & $20(-72 ; 96)$ \\
\hline
\end{tabular}

$\mathrm{CI}=$ Confidence interval; EQ-5D = EQ-5D descriptive system; QALYs = quality-adjusted life years; SDS-BMI _ standard deviation of BMI, NA = not applicable.

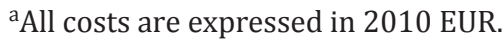

${ }^{b}$ Healthcare costs are the sum of the primary healthcare costs (e.g. cost of a general practitioner) and secondary healthcare costs (e.g. cost of a hospital-based physicians). 
Table 5. Differences in pooled and mean costs and effects ( $95 \%$ confidence intervals), incremental cost-effectiveness ratios and the distribution of incremental cost-effect pairs around the quadrants of the cost-effectiveness planes

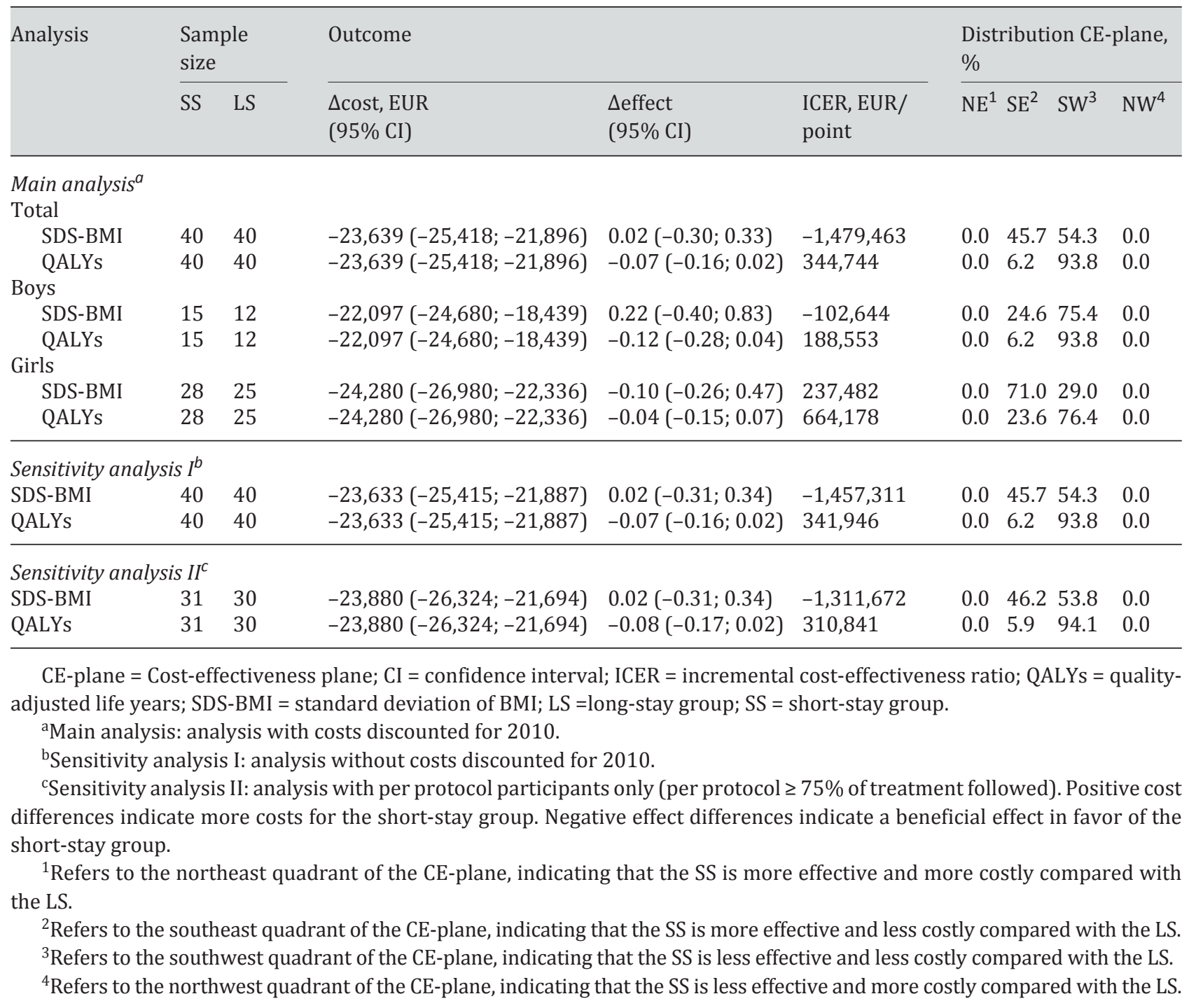

\section{Costs}

Mean total costs in the short-stay group were statistically significantly lower than in the long-stay group (mean difference-23,639 EUR). Treatmentcosts were the greatest contributor to this cost difference. In the short-stay group, healthcare costs were significantly higher and transportation costs significantly lower than in the long-stay group (table 4).

\section{Economic Evaluation}

The results of the CEA and CUA are presented in table 5. For SDS-BMI, the ICER was $-1,479,463$ EUR per point SDS-BMI indicating that one point higher in SDS-BMI in the shortstay group is associated with savings of 1,479,463 EUR in comparison with the long-stay group. The difference in SDS-BMI between both groups after 24 months was very small leading to this very large ICER that is difficult to interpret. In the CE-plane, 46\% and 54\% of the incremental cost-effect pairs were located in the South-East and South-West quadrants, 
Fig. 2. SDS-BMI for the short-stay and long-stay group during 24 months of follow-up. Error bars indicate standard error (SE) of the mean.

Makkes et al.: Economic Evaluation of Intensive Inpatient Treatments for Severely Obese Children and Adolescents

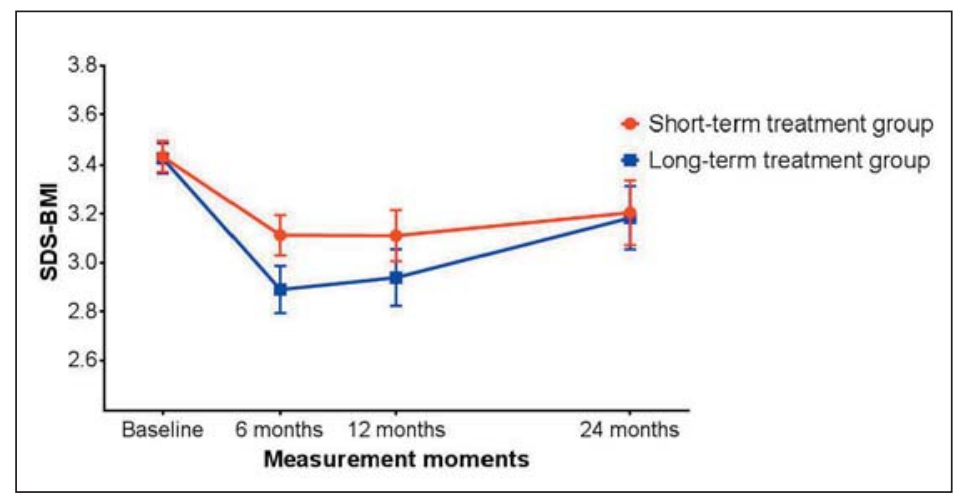

Fig. 3. Cost-effectiveness plane for the difference in a SDS-BMI and $\mathbf{b}$ QUALYs at 24 months (societal perspective).

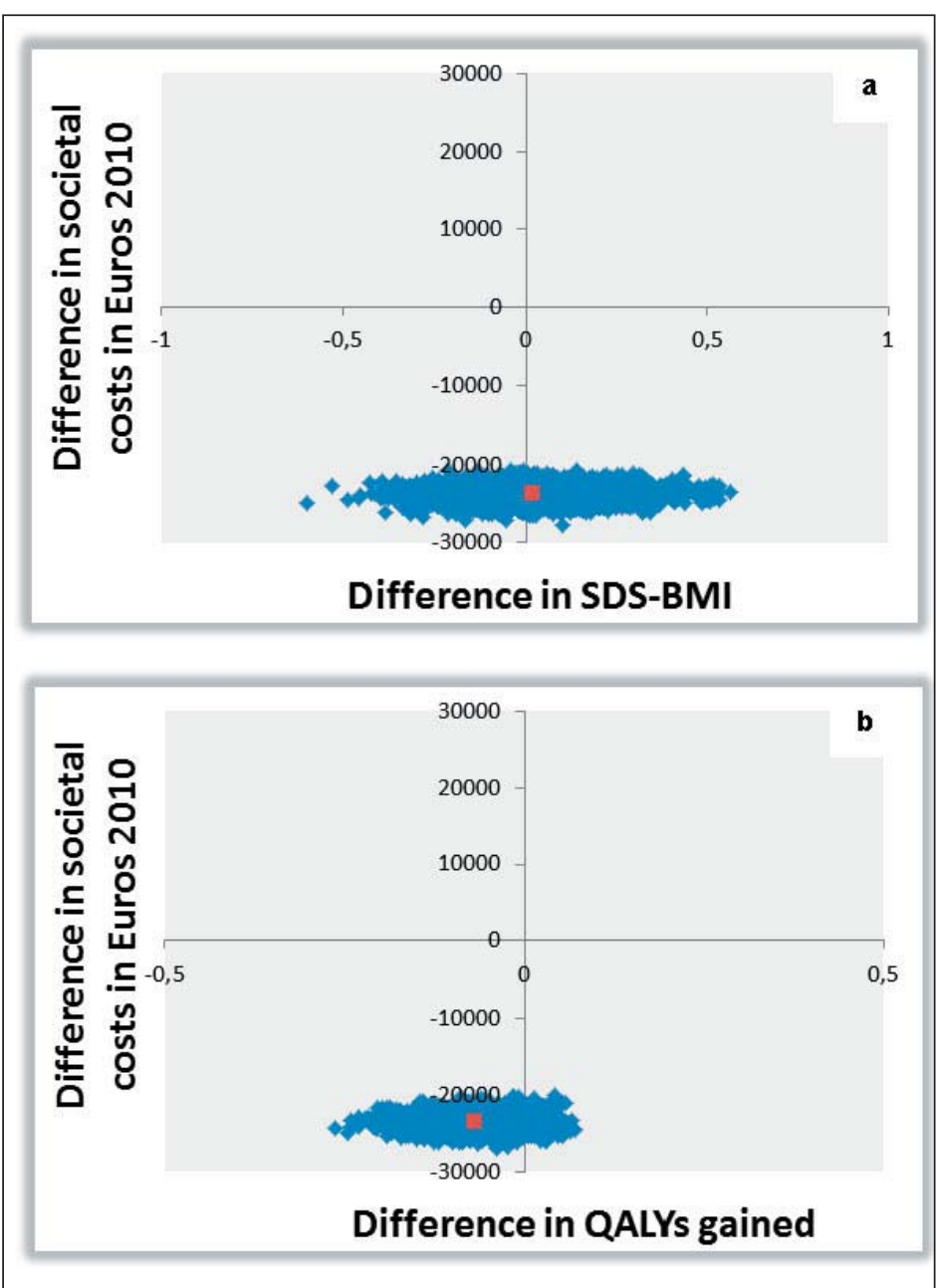

respectively (fig. 3a), confirming the small difference in effects between the groups and the statistically significant difference in costs. The CEAC for SDS-BMI shows that the probability of the short-stay treatment being cost-effective in comparison with the long-stay treatment is 1 at all values of willingness-to-pay between 0 and 50,000 EUR/point SDS-BMI, after which it gradually decreased with increasing values of willingness-to-pay (fig. $4 \mathrm{a}$ ). 
Fig. 4. Cost-effectiveness acceptability curve for the difference in a SDS-BMI and b QUALYs at 24 months (societal perspective).
Makkes et al.: Economic Evaluation of Intensive Inpatient Treatments for Severely Obese Children and Adolescents

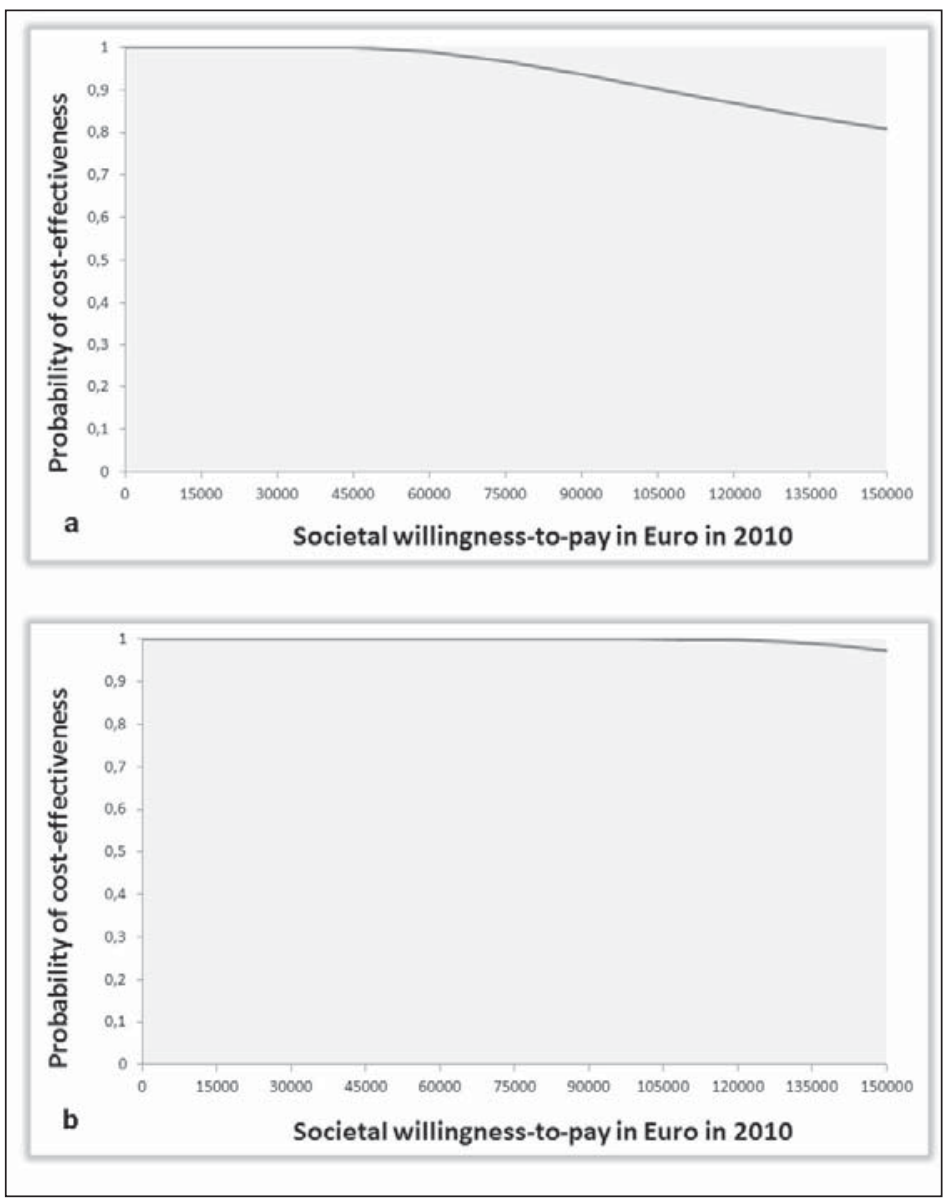

An ICER of 344,744 was found for QALYs at 24 months, meaning that one point decrease in QALY in the short-stay group is associated with savings of 344,744 EUR in comparison with the long-stay group (fig. $3 \mathrm{~b}$ ). The CEAC for QALYs shows that the probability of the short-stay treatment being cost-effective in comparison with the long-stay treatment is 1 at all values of willingness-to-pay between 0 and 83,000 EUR/QALY gained, after which it slightly decreased with increasing values of willingness-to-pay (fig. $4 \mathrm{~b}$ ).

\section{Sensitivity Analyses}

The overall conclusions did not change in the sensitivity analyses (table 5). However, a post-hoc analysis revealed different effects for boys and girls. The results for boys were in line with the main analyses, namely a difference in SDS-BMI between the groups in favor of the long-stay group. Although this difference was larger than in the main analysis, it was still not statistically significant. However, in girls the difference in SDS-BMI was in favor of the shortstay group. The ICER indicates that one point decrease in SDS-BMI in the short-stay group in comparison with the long-stay group is associated with savings of 237,482 EUR. For QALYs gained results were similar to the main analyses for both sexes. 
Makkes et al.: Economic Evaluation of Intensive Inpatient Treatments for Severely Obese Children and Adolescents

\section{Discussion}

The present study aimed to conduct an economic evaluation comparing two intensive 1-year treatments with varying inpatient periods for severely obese children and adolescents with regard to SDS-BMI and QALYs, with an additional year of follow-up. In both groups, SDS-BMI decreased during the 1st 6-month period, stabilized during the 2nd 6-month period, after which it slightly increased. It is noteworthy that such a decrease in effect during the 2 nd year of follow-up was not found for health-related quality of life (i.e. utilities). An explanation for this might be that psychological benefits of the intervention were maintained in the 2nd year, whereas physical benefits (e.g. weight loss) were not. But further research is needed to establish this. Societal costs were significantly lower for the short-stay group in comparison with the long-stay group with treatment costs being the main contributor. The higher healthcare costs among participants in the short-stay group can be explained by the fact that they were more dependent on healthcare outside the center as their inpatient period was shorter. Parents/caregivers in the long-stay group had higher travelling costs as they had to travel to the center more frequently during the 1st half year of treatment. Contrary to our expectations, lost productivity costs were highest in the short-stay group. CE-planes and CEACs showed that the short-stay treatment was cost-effective in comparison with the longstay treatment for values of willingness-to-pay ranging from 0 to 83,000 EUR/QALY gained and from 0 to 163,000 EUR/point SDS-BMI.

Only few studies evaluated the effectiveness of obesity treatments in severely obese children and adolescents. Most studies showed weight loss during the intensive treatment period, but weight gain during follow-up [46-50]. Two studies evaluated treatments including an inpatient period, similar to our study. They reported substantial weight loss directly after treatment [51, 52]; however, long-term results were not presented. Our study confirms the effectiveness of inpatient treatment for severely obese children and adolescents on SDS-BMI, but this was not maintained during 1 year of follow-up after treatment. Kelly et al. [51]. stated that the ultimate goal of behavioral interventions should be to improve the quality of life in children and adolescents with severe obesity In our study, utility scores increased by 0.11 points on a scale of 0.0-1.0 in both groups during the 1-year treatment. Remarkably, this improvement in quality of life was maintained during the additional year of follow-up with no statistically significant difference between groups, despite an increase in SDS-BMI during that year.

\section{Strengths and Limitations}

This study has several strengths. First, to our knowledge, this study was the first to evaluate the (cost-)effectiveness of inpatient treatments for severely obese children and adolescents. Secondly, this study was designed as a randomized controlled trial, reducing the risk of bias [53]. Moreover, costs and effects were collected prospectively under 'real life' conditions. Thirdly, the CEA was conducted from a societal perspective, which meant that not only treatment costs were taken into account, but also the costs of healthcare utilization, transportation, and lost productivity of the parents/caregivers, although these were relatively low. Fourthly, the total follow-up of 24 months was relatively long in comparison with other studies carried out among youth with severe obesity.

There are also some limitations of our study. Firstly, the high rate of missing data; only $24 \%$ had complete cost data available in the last half year of follow-up. Multiple imputation was used to deal with missing data, to avoid the inefficiency associated with complete-case analyses, and to prevent bias through selective drop-out [42]. Secondly, since the power calculation was based on detecting a difference of 0.5 SDS-BMI, the study was underpowered to detect relevant cost differences, which was reflected in wide confidence intervals around 
the cost differences. Thirdly, as Dutch utility tariffs are lacking for quality-of-life instruments for children and adolescents (e.g. EQ-5D-Y, YQOL, KINDL-R), we opted to use the EQ-5D for estimating QALYs. The EQ-5D, however, was originally designed for use in adult populations, which may limit the validity of the EQ-5D in measuring quality of life in children and adolescents. Finally, no usual care group was included in the present CEA, because participants who were allocated to the weight list group during the 1st year of follow-up, were allocated to one of the treatment groups during the 2nd year of follow-up [28].

\section{Implications}

For severely obese children and adolescents with insufficient response to ambulatory obesity treatment, inpatient treatment may be a promising alternative [41]. However, definitive conclusions regarding the cost-effectiveness of the short-stay treatment should be postponed until information is available about the cost-effectiveness in comparison with usual care. In our study the weight loss was promising during the intensive treatment, although it was not maintained during 1 year of follow-up after treatment. Investments in intensive treatments will only be justified if weight loss is sustained over a longer period after treatment. Moreover, maintenance of weight loss is necessary to prevent the long-term health and economic burden of childhood obesity. Therefore, continuous treatment, monitoring, and periodic intensive return visits after intensive treatment seem essential to ensure long-term maintenance of weight loss [30]. In our study, continuation of the monthly return visits of 2 days for 1 year after treatment has ended will lead to additional costs of 7,878 EUR per participant. Future studies should evaluate whether costs of such intensive follow-up weigh up against the effects. On the other hand, inpatient treatment is costly and poses a high burden on the families participating; so preferably this continuous treatment is organized in the home environment making it more feasible and less expensive than intensive treatment in specialized childhood obesity centers.

\section{Conclusion}

Inpatient treatment may be a promising alternative for severely obese children and adolescents with insufficient response to ambulatory obesity treatment. After 24 months, there were no differences in SDS-BMI and QALYs gained between the groups. Costs were significantly lower for the short-stay treatment in comparison with the long-stay treatment. Based on these results, the short-stay treatment can be regarded as cost-effective from the societal perspective in comparison with the long-stay treatment.

\section{Contributors' Statement}

Sabine Makkes contributed to the acquisition of data, carried out the statistical analyses and interpreted the data, drafted the initial manuscript, reviewed and revised the manuscript, and approved the final manuscript as submitted.

Johanna M. van Dongen carried out the statistical analyses and interpreted the data, drafted the initial manuscript, reviewed and revised the manuscript, and approved the final manuscript as submitted.

Carry M. Renders drafted the initial manuscript, reviewed and revised the manuscript, and approved the final manuscript as submitted.

Olga H. van der Baan-Slootweg conceptualized and designed the study, contributed to the acquisition of data, reviewed and revised the manuscript, and approved the final manuscript as submitted.

Jacob C. Seidell conceptualized and designed the study, reviewed and revised the manuscript, and approved the final manuscript as submitted. 
Judith E. Bosmans drafted the initial manuscript, reviewed and revised the manuscript, and approved the final manuscript as submitted.

All authors agree to be accountable for all aspects of the work.

\section{Ethical Approval of Studies and Informed Consent}

The Science Committee (SC) approved of the methodological quality of the research proposal. After this approval by the SC, the Medical Ethics committee (METc) of VU University Medical Center evaluated and approved the study design, protocol and informed consent procedures. Written informed consents were obtained from both the participants and their parents/caregivers.

\section{Acknowledgements}

We acknowledge the assistance of Ottelien van Weelden for contributing to the data collection and Michelle Belder, Maaike van de Bovenkamp and Hester Lust for entering data in the database. Also we would like to thank all the other professionals at Merem Childhood Obesity Center, Heideheuvel for their assistance in the treatments and in the acquisition of data. Furthermore we would like to thank the participants and their parents/caregivers participating in this study.

\section{Data Access, Responsibility, and Analysis}

Sabine Makkes and Hanneke van Dongen had full access to all data in the study and take responsibility for the integrity of the data and the accuracy of the data analyses.

\section{Funding}

All phases of this study were supported by the Netherlands Organization for Health Research and Development (ZonMw), 17099.2001.

\section{Clinical Trial Registration}

Netherlands Trial Register (NTR): NTR1678.

\section{Disclosure Statement}

The authors have no financial relationships relevant to this article to disclose. OHBS is affiliated with the treatments as pediatrician. Other than that the authors declare no conflicts of interest.

\section{References}

1 Jackson-Leach R, Lobstein T: Estimated burden of paediatric obesity and co-morbidities in Europe. Part 1. The increase in the prevalence of child obesity in Europe is itself increasing. Int J Pediatr Obes 2006;1:26-32.

2 Ogden CL, Carroll MD, Kit BK, Flegal KM: Prevalence of obesity in the United States, 2009-2010. NCHS Data Brief 2012;82:1-8.

3 Schönbeck Y, Talma H, van Dommelen P, Bakker B, Buitendijk SE, HiraSing RA, van Buuren S: Increase in prevalence of overweight in Dutch children and adolescents: a comparison of nationwide growth studies in 1980, 1997 and 2009. PloS One 2011;6:e27608.

4 Skelton JA, Cook SR, Auinger P, Klein JD, Barlow SE: Prevalence and trends of severe obesity among us children and adolescents. Acad Pediatr 2009;9:322-329. 
5 Yang L, Colditz GA: Prevalence of overweight and obesity in the United States, 2007-2012. JAMA Intern Med 2015;175:1412-1413.

6 Statistics Netherlands: Lengte en gewicht van personen, ondergewicht en overgewicht; vanaf 1981, 2016.

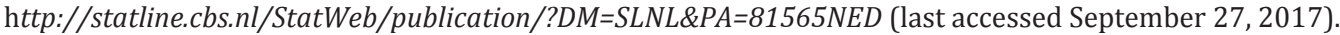

7 Dietz WH: Health consequences of obesity in youth: childhood predictors of adult disease. Pediatrics 1998; 101:518-525.

8 Franks PW, Hanson RL, Knowler WC, Sievers ML, Bennett PH, Looker HC: Childhood obesity, other cardiovascular risk factors, and premature death. N Engl J Med 2010;362:485-493.

9 Ludwig DS: Childhood obesity - the shape of things to come. N Engl J Med 2007;357:2325-2327.

10 Berenson GS: Health consequences of obesity. Pediatr Blood Cancer 2012;58:117-121.

11 Makkes S, Renders CM, Bosmans JE, van der Baan-Slootweg OH, Seidell JC: Cardiometabolic risk factors and quality of life in severely obese children and adolescents in the Netherlands. BMC Pediatr 2013;13:1.

12 Falkner NH, Neumark-Sztainer D, Story M, Jeffery RW, Beuhring T, Resnick MD: Social, educational, and psychological correlates of weight status in adolescents. Obes Res 2001;9:32-42.

13 Puder J, Munsch S: Psychological correlates of childhood obesity. Int J Obes 2010;34:S37-S43.

14 Van Wijnen LG, Boluijt PR, Hoeven-Mulder HB, Bemelmans WJ, Wendel-Vos GW: Weight status, psychological health, suicidal thoughts, and suicide attempts in Dutch adolescents: RESULTS from the 2003 e-movo project. Obesity (Silver Spring) 2010;18:1059.

15 Schwimmer JB, Burwinkle TM, Varni JW: Health-related quality of life of severely obese children and adolescents. JAMA 2003;289:1813-1819.

16 Zeller MH, Roehrig HR, Modi AC, Daniels SR, Inge TH: Health-related quality of life and depressive symptoms in adolescents with extreme obesity presenting for bariatric surgery. Pediatrics 2006;117:1155-1161.

17 Trasande L, Chatterjee S: The impact of obesity on health service utilization and costs in childhood. Obesity (Silver Spring) 2009;17:1749-1754.

18 Withrow D, Alter D: The economic burden of obesity worldwide: a systematic review of the direct costs of obesity. Obes Rev 2011;12:131-141.

19 Trasande L, Elbel B: The economic burden placed on healthcare systems by childhood obesity. Expert Rev Pharmacoecon Outcomes Res 2012;12:39-45.

20 Batscheider A, Rzehak P, Teuner CM, Wolfenstetter SB, Leidl R, von Berg A, Berdel D, Hoffmann B, Heinrich J: Development of BMI values of German children and their healthcare costs. Econ Hum Biol 2014;12:56-66.

21 Singh AS, Mulder C, Twisk JW, Van Mechelen W, Chinapaw MJ: Tracking of childhood overweight into adulthood: a systematic review of the literature. Obes Rev 2008;9:474-488.

22 Freedman DS, Mei Z, Srinivasan SR, Berenson GS, Dietz WH: Cardiovascular risk factors and excess adiposity among overweight children and adolescents: THE Bogalusa Heart Study. J Pediatr 2007;150:12-17. e12.

23 Baker JL, Olsen LW, Sørensen TI: Childhood body-mass index and the risk of coronary heart disease in adulthood. N Engl J Med 2007;357:2329-2337.

24 Sonntag D, Ali S, Lehnert T, Konnopka A, Riedel-Heller S, König HH: Estimating the lifetime cost of childhood obesity in Germany: results of a Markov model. Pediatr Obes 2015;10:416-422.

25 Trasande L: How much should we invest in preventing childhood obesity? Health Affairs 2010;29:372-378

26 Krebs NF, Himes JH, Jacobson D, Nicklas TA, Guilday P, Styne D: Assessment of child and adolescent overweight and obesity. Pediatrics 2007;120(suppl 4):S193-S228.

27 Seidell J, Halberstadt J, Noordam H, Niemer S: An integrated health care standard for the management and prevention of obesity in the Netherlands. Fam Pract 2012;29:i153-i156.

28 Makkes S, Halberstadt J, Renders CM, Bosmans JE, van der Baan-Slootweg OH, Seidell JC: Cost-effectiveness of intensive inpatient treatments for severely obese children and adolescents in the Netherlands; a randomized controlled trial (HELIOS). BMC Public Health 2011;11:1.

29 Oude Luttikhuis H, Baur L, Jansen H, Shrewsbury VA, O'Malley C, Stolk RP, Summerbell CD: Interventions for treating obesity in children. Cochrane Database Syst Rev 2009;1:CD001872.

30 Kelly AS, Barlow SE, Rao G, Inge TH, Hayman LL, Steinberger J, Urbina EM, Ewing LJ, Daniels SR: Severe obesity in children and adolescents: identification, associated health risks, and treatment approaches a scientific statement from the American Heart Association. Circulation 2013;128:1689-1712.

31 Hirasing R, Fredriks A, Van Buuren S, Verloove-Vanhorick S, Wit J: Increased prevalence of overweight and obesity in Dutch children, and the detection of overweight and obesity using international criteria and new reference diagrams (in Dutch). Nederlands Tijdschrift voor Geneeskunde 2001;145:1303-1308.

32 Pocock SJ: Clinical Trials: A Practical Approach. New York, Wiley \& Sons, 2013.

33 Cole TJ, Bellizzi MC, Flegal KM, Dietz WH: Establishing a standard definition for child overweight and obesity worldwide: international survey. BMJ 2000;320:1240.

34 Stichting Kind en Groei: Growth analyzer, 2010. http://kindengroei.nl/stichting-kind-en-groei/kindergroeimeter/ (last accessed September 27, 2017).

35 EuroQol Group: EuroQol - a new facility for the measurement of health-related quality of life. Health Policy 1990;16:199-208.

36 Lamers L, Stalmeier P, McDonnell J, Krabbe P, van Busschbach J: Measuring the quality of life in economic evaluations: the Dutch eq-5d tariff (in Dutch). Nederlands Tijdschrift voor Geneeskunde 2005;149:15741578. 
37 Hakkaart-van Roijen L, Tan S, Bouwmans C: Methods and standard cost prices for economic evaluations in healthcare (in Dutch). Version 2010, Diemen, College van Zorgverzekeringen, 2011.

38 Brouwer WB, Van Exel N, Baltussen RM, Rutten FF: A dollar is a dollar is a dollar - or is it? Value Health 2006; 9:341-347.

39 van Dongen JM, van Wier MF, Tompa E, Bongers PM, van der Beek AJ, van Tulder MW, Bosmans JE: Trial-based economic evaluations in occupational health: principles, methods, and recommendations. J Occup Environl Med 2014;56:563.

40 Statistics Netherlands: Consumenten prijs index. 2011. http://nl.inflation.eu/inflatiecijfers/nederland/historische-inflatie/cpi-inflatie-nederland.aspx (last accessed September 27, 2017).

41 van der Baan-Slootweg O, Benninga MA, Beelen A, van der Palen J, Tamminga-Smeulders C, Tijssen JG, van Aalderen WM: Inpatient treatment of children and adolescents with severe obesity in the Netherlands: a randomized clinical trial. JAMA Pediatr 2014;168:807-814.

42 White IR, Royston P, Wood AM: Multiple imputation using chained equations: issues and guidance for practice. Stat Med 2011;30:377-399.

43 Willan AR, Briggs AH, Hoch JS: Regression methods for covariate adjustment and subgroup analysis for noncensored cost-effectiveness data. Health Econ 2004;13:461-475.

44 Black WC: The CE plane a graphic representation of cost-effectiveness. Med Decis Making 1990;10:212-214.

45 Fenwick E, O’Brien BJ, Briggs A: Cost-effectiveness acceptability curves - facts, fallacies and frequently asked questions. Health Econ 2004;13:405-415.

46 Levine MD, Ringham RM, Kalarchian MA, Wisniewski L, Marcus MD: Is family-based behavioral weight control appropriate for severe pediatric obesity? Int J Eat Disord 2001;30:318-328.

47 Johnston CA, Tyler C, Palcic JL, Stansberry SA, Gallagher MR, Foreyt JP: Smaller weight changes in standardized body mass index in response to treatment as weight classification increases. J Pediatr 2011;158:624-627.

48 Savoye M, Shaw M, Dziura J, Tamborlane WV, Rose P, Guandalini C, Goldberg-Gell R, Burgert TS, Cali AM, Weiss R: Effects of a weight management program on body composition and metabolic parameters in overweight children: a randomized controlled trial. JAMA 2007;297:2697-2704.

49 Danielsson P, Kowalski J, Ekblom Ö, Marcus C: Response of severely obese children and adolescents to behavioral treatment. Arch Pediatr Adolesc Medic 2012;166:1103-1108.

50 Kalarchian MA, Levine MD, Arslanian SA, Ewing LJ, Houck PR, Cheng Y, Ringham RM, Sheets CA, Marcus MD: Family-based treatment of severe pediatric obesity: randomized, controlled trial. Pediatrics 2009;124:10601068.

51 Knöpfli BH, Radtke T, Lehmann M, Schätzle B, Eisenblätter J, Gachnang A, Wiederkehr P, Hammer J, BrooksWildhaber J: Effects of a multidisciplinary inpatient intervention on body composition, aerobic fitness, and quality of life in severely obese girls and boys. J Adolesc Health 2008;42:119-127.

52 Rolland-Cachera M, Thibault H, Souberbielle J, Soulie D, Carbonel P, Deheeger M, Roinsol D, Longueville E, Bellisle F, Serog P: Massive obesity in adolescents: dietary interventions and behaviours associated with weight regain at 2 y follow-up. Int J Obes 2004;28:514-519.

53 Petrou S, Gray A: Economic evaluation alongside randomised controlled trials: design, conduct, analysis, and reporting. BMJ 2011;342:d1548. 